\title{
Comparing genetic diversity and demographic history in co- distributed wild South American camelids
}

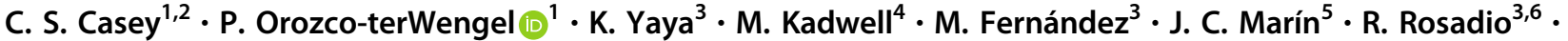 \\ L. Maturrano ${ }^{3,6} \cdot$ D. Hoces ${ }^{3} \cdot$ Y. Hu ${ }^{7} \cdot$ J. C. Wheeler ${ }^{3} \cdot$ M. W. Bruford ${ }^{1,3}$
}

Received: 18 September 2017 / Revised: 11 May 2018 / Accepted: 28 May 2018 / Published online: 30 July 2018

(c) The Genetics Society 2018

\begin{abstract}
Vicuñas and guanacos are two species of wild South American camelids that are key ruminants in the ecosystems where they occur. Although closely related, these species feature differing ecologies and life history characters, which are expected to influence both their genetic diversity and population differentiation at different spatial scales. Here, using mitochondrial and microsatellite genetic markers, we show that vicuña display lower genetic diversity within populations than guanaco but exhibit more structure across their Peruvian range, which may reflect a combination of natural genetic differentiation linked to geographic isolation and recent anthropogenic population declines. Coalescent-based demographic analyses indicate that both species have passed through a strong bottleneck, reducing their effective population sizes from over 20,000 to less than 1000 individuals. For vicuña, this bottleneck is inferred to have taken place $\sim 3300$ years ago, but to have occurred more recently for guanaco at 2000 years ago. These inferred dates are considerably later than the onset of domestication (when the alpaca was domesticated from the vicuña while the llama was domesticated from the guanaco), coinciding instead with a major human population expansion following the mid-Holocene cold period. As importantly, they imply earlier declines than the well-documented Spanish conquest, where major mass mortality events were recorded for Andean human and camelid populations. We argue that underlying species' differences and recent demographic perturbations have influenced genetic diversity in modern vicuña and guanaco populations, and these processes should be carefully evaluated in the development and implementation of management strategies for these important genetic resources.
\end{abstract}

These authors contributed equally: C.S. Casey, P. Orozco-terWengel

Electronic supplementary material The online version of this article (https://doi.org/10.1038/s41437-018-0120-z) contains supplementary material, which is available to authorized users.

\section{J. C. Wheeler}

janecwheeler@conopa.org

$\triangle$ M. W. Bruford

brufordmw@cf.ac.uk

1 School of Biosciences, Cardiff University, Cathays Park, Cardiff CF10 3AX, UK

2 School of Life Sciences, University of Lincoln, Riseholme Park, Lincoln LN2 2LG, UK

3 CONOPA, Instituto de Investigación y Desarrollo de Camélidos Sudamericanos, Avenida Reusche Mz. M Lt. 4, Pachacamac,

\section{Introduction}

Population and evolutionary genetic studies often seek to identify ecological and evolutionary patterns and processes for multiple species inhabiting the same ecosystem to provide a more reliable overview of the forces that shape the distribution of genetic diversity today (Romiguier et al. 2014). However, even for ecologically similar or

Lima 19, Peru

4 Institute of Zoology, Zoological Society of London, Regent's Park, London NW1 4RY, UK

5 Departamento de Ciencias Básicas, Facultad de Ciencias, Universidad del Bío - Bío, Casilla 447, Chillan, Chile

6 Facultad de Medicina Veterinaria, Universidad Nacional Mayor de San Marcos, Lima, Peru

7 Key Laboratory of Animal Ecology and Conservation Biology, Institute of Zoology, Chinese Academy of Sciences, 1-5 Beichen West Road, 100101 Beijing, China 
taxonomically related organisms, it is not clear how comparable fine-scale processes might be, given the myriad of events that shape each species' history and interactions (e.g., Kunkel et al. 2013). Focusing on two closely related wild South American camelids, emblematic to the Andean mountain chain and southern grasslands, we assessed how their demographic history has shaped their genetic variation. The guanaco (Lama guanicoe) is the largest artiodactyl in South America and the wild ancestor of the domestic llama (Lama glama), while the vicuña (Vicugna vicugna), which possesses some of the finest and most valuable natural fibre in the world, is the wild ancestor of the domestic alpaca (Vicugna pacos; Kadwell et al. 2001). Both wild species are taxonomically recognised as having two subspecies. In Peru, the resident subspecies ( $L$. g. cacsilensis and $V$. v. mensalis) have a chequered recent history due to anthropogenic influence beginning with the Spanish conquest involving uncontrolled exploitation, and both are of conservation concern with the current Peruvian national classification describing them as critically endangered and near threatened, respectively. In 1969, Grimwood described the Peruvian guanaco population to be 'on the edge of extinction' (Grimwood 1969), and in 1971 the Peruvian government declared it an endangered species. Although today, there are $\sim 550,000$ guanacos in the wild across its range (IUCN 2010), the Peruvian population remains very low with as few as 3000 animals left, mostly occurring at very low densities (Wheeler et al. 2006). The vicuña, on the other hand, has recovered from a population size of fewer than 5000 individuals (Grimwood 1969), less than $1 \%$ of the estimated pre-Hispanic population (Brack 1980), to $\sim 210,000$ in Peru (INEI 2013) at present ( 347,000 across the entire Andes; IUCN 2010). This outcome is the result of strong conservation efforts to reduce poaching, as well as promoting sustainable fibre utilisation involving live animal shearing and legal sale of fibre by local Andean communities. Guanacos (L. g. cacsilensis) are managed in similar ways in Peru and northern Chile, largely focusing on population protection, although not all Peruvian populations occur in protected areas (e.g., national parks; Baldi et al. 2016). Contrastingly, the vicuña (V. v. mensalis) in Peru are captured using ancient Inca rituals (chaccu) and sheared for their fleece, while in northern Chile these occur in natural parks and reserves, where they are protected (Lichtenstein et al. 2008).

Vicuñas and guanacos overlap throughout their range in the Andes of Peru and Chile, including a number of protected areas, where the vicuña is confined to areas of extreme elevation $\left(>3800 \mathrm{~m}\right.$ ) between $9^{\circ} 08^{\prime}$ and $18^{\circ} 55^{\prime} \mathrm{S}$. However, throughout their distribution, the two exhibit markedly different ecology and behaviour (see Table S1 for a summary). Most notably, the vicuña is a high-altitude plains specialist while the guanaco is an altitudinal generalist and is found from the coast to the Andean plateau between $8^{\circ} 00^{\prime}$ and $18^{\circ} 30^{\prime} \mathrm{S}$; the vicuña requires moist conditions and consumes food with high water content, whereas the guanaco lives a significant amount of its time in desert and browses when necessary. The vicuña lives in larger, territorial family groups and has large non-territorial bachelor groups, whereas the guanaco lives in smaller, mobile family units, the cohesion of which are currently unknown (Table S1; Frankin 1983; Wheeler 2012a). Due to such differences these two wild camelids cannot be easily managed similarly, although that has been the approach taken in several South American countries to date, including Peru (e.g., Hoces 2005). Furthermore, it is expected that differences in social structure, habitat specificity and other life history characters should be reflected in their withinand among-population genetic variation (e.g., Hamilton et al. 2005; Ross 2001). If this is indeed the case, genetic management of these two species may need to be carried out differently, especially if their large-scale genetic structure is markedly different.

Genetic analyses of wild camelids to date have not focused on comparing the genetic structure in sympatric populations. Studies on single species have been published using microsatellites and mitochondrial (mt) DNA, for example, on populations of the guanaco in Chile and Argentina (Anello et al. 2016; Bustamante et al. 2002; Gonzalez et al. 2014; Sarno et al. 2001). Marín et al. (2008) analysed mtDNA across its entire native range, but failed to show evidence for subspecies as distinct evolutionary lineages and instead indicated a rapid post-Pleistocene population expansion. Marín et al. (2008) also concluded that microsatellite analysis of $L$. g. cacsilensis would be required to show a 'clearer pattern of genetic variation among subpopulations'. However, only a limited microsatellite-based analysis has been published on $L$. $g$. cacsilensis so far (Marín et al. 2013), in which two relatively differentiated genetic groups were identified, although some degree of genetic contact between the two was suggested. To date, one study has documented the mtDNA genetic variation in the vicuña (Marín et al. 2007), supporting the current taxonomic status of the species dividing it into two evolutionary lineages, i.e., a northern lineage corresponding to $V$. v. mensalis, and a southern lineage corresponding to $V$. v. vicugna. A preliminary study of microsatellite variation in Peruvian vicuñas (Dodd et al. 2006) inferred the presence of up to four genetically differentiated populations; however, how these results reflect genetic variation in the rest of the species' range is yet unknown. However, these studies largely represent nonoverlapping data sets for each species limiting the conclusions that can be derived across studies.

Here, we compare the genetic diversity and structure of guanaco ( $L$. g. cacsilensis) and vicuña (V. v. mensalis) 
Fig. 1 Sampling locations in Peru and Chile for (a) vicuña (Vicugna vicugna mensalis) and b guanaco Lama guanicoe cacsilensis analysed in this study with detail of the Peruvian and northern Chilean Andean cordilleras. Sampling locations are shown with empty circles for vicuña and full squares for guanaco. The light grey-shaded area corresponds to the distribution range of $V . v$. mensalis, and the black areas to that of $L$. g. cacsilensis. The results of STRUCTURE for $K$ $=2$ are shown next to the map for each species, as well as contour lines on the map corresponding to the clusters identified with STRUCTURE for $K=2$ (colours correspond to those in Fig. 2)
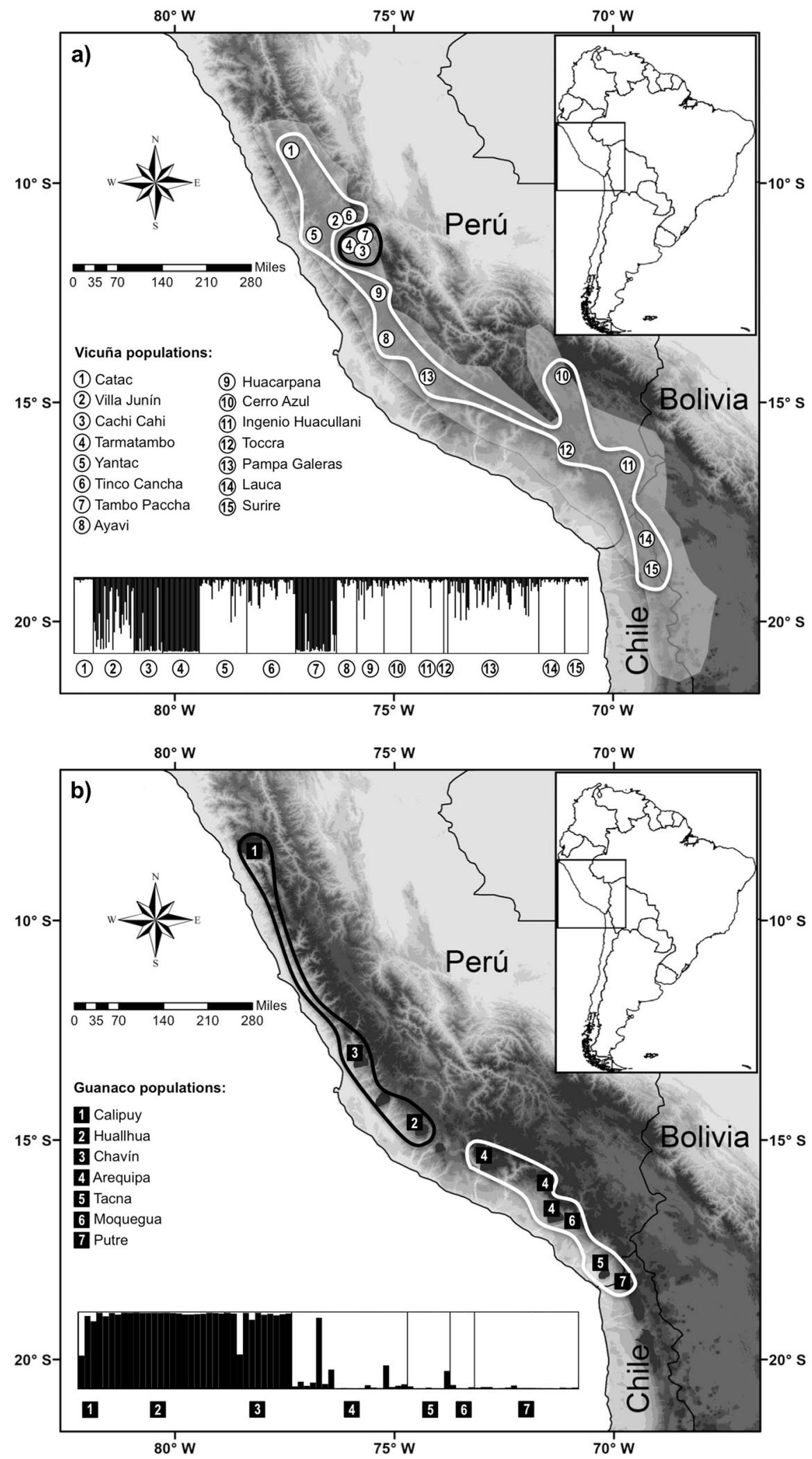

populations from Peru and northern Chile using microsatellite and mitochondrial data. We use these data to compare the demographic histories of these species and to address the following hypotheses: (1) within-population genetic variation in the Peruvian guanaco is lower than that of the Peruvian vicuña reflecting the guanaco's current 
Table 1 Genetic variation for microsatellites $(n=11$ and 16 loci, respectively) in vicuña and guanaco populations

\begin{tabular}{|c|c|c|c|c|c|c|}
\hline \multirow{3}{*}{ Vicuña } & \multicolumn{2}{|c|}{ Sample size } & \multirow[t]{2}{*}{$\mathrm{H}_{\mathrm{o}}$} & \multirow[t]{2}{*}{$\mathrm{H}_{\mathrm{e}}$} & \multirow[t]{2}{*}{ ANAPL } & \multirow[t]{2}{*}{$F_{\text {IS }}$} \\
\hline & mtDNA & Microsatellites & & & & \\
\hline & 139 & 377 & 0.442 & 0.489 & 4.15 & 0.060 \\
\hline Catac & $\mathrm{B}(8)$ & $\mathrm{B}(14)$ & 0.429 & 0.368 & 2.3 & $-0.171 *$ \\
\hline Villa Junin & $\mathrm{B}(3)$ & $\mathrm{B}(30)$ & 0.332 & 0.413 & 3.9 & $0.20 *$ \\
\hline Cachi Cachi & $\mathrm{B}(4)$ & $\mathrm{B}(21)$ & 0.414 & 0.427 & 3.1 & 0.03 \\
\hline Tarmatambo & $\mathrm{B}(2)$ & $\mathrm{B}(27)$ & 0.368 & 0.380 & 2.5 & 0.03 \\
\hline Yantac & $\mathrm{B}(18)$ & $\mathrm{B}(35)$ & 0.377 & 0.468 & 4.0 & $0.197 *$ \\
\hline Tinco Cancha & $\mathrm{B}(16)$ & $\mathrm{B}(36)$ & 0.505 & 0.549 & 4.5 & $0.082 *$ \\
\hline Tambo Paccha & $\mathrm{B}(16)$ & $\mathrm{B}(30)$ & 0.350 & 0.375 & 3.1 & 0.068 \\
\hline Ayavi & $\mathrm{B}(5)$ & $\mathrm{B}(15)$ & 0.442 & 0.492 & 4.0 & $0.103^{*}$ \\
\hline Huacarpana & $\mathrm{B}(17)$ & $\mathrm{B}(20)$ & 0.468 & 0.494 & 4.8 & 0.053 \\
\hline Cerro Azul & $\mathrm{B}(9)$ & $\mathrm{B}(20)$ & 0.455 & 0.518 & 5.6 & $0.125^{*}$ \\
\hline Ingenio Huacullani & $\mathrm{B}(16)$ & $\mathrm{B}(24)$ & 0.464 & 0.534 & 5.2 & $0.135^{*}$ \\
\hline Toccra & $\mathrm{B}(3)$ & $\mathrm{B}(3)$ & 0.455 & 0.533 & 2.6 & 0.178 \\
\hline Pampa Galeras & $\mathrm{B}(6)$ & $\mathrm{B}(66)$ & 0.545 & 0.611 & 5.7 & $0.11 *$ \\
\hline Lauca & $\mathrm{B}(11)$ & $\mathrm{B}(16), \mathrm{D}(3)$ & 0.517 & 0.594 & 5.4 & 0.128 \\
\hline Surire & $\mathrm{B}(5)$ & $\mathrm{B}(16), \mathrm{D}(1)$ & 0.523 & 0.610 & 5.5 & $0.147 *$ \\
\hline Guanaco & 50 & 82 & 0.642 & 0.667 & 4.211 & -0.089 \\
\hline Calipuy & $F(10)^{\&}$ & $\mathrm{~F}(3)$ & 0.528 & 0.514 & 2.0 & -0.06 \\
\hline Chavin & $\mathrm{F}(3)$ & $\mathrm{F}(11)$ & 0.591 & 0.659 & 4.9 & $0.11^{*}$ \\
\hline Huallhua & $\mathrm{B}(11)$ & $\mathrm{B}(11), \mathrm{F}(10)$ & 0.679 & 0.695 & 5.4 & 0.025 \\
\hline Arequipa & $\mathrm{F}(14)$ & $\mathrm{F}(19)$ & 0.684 & 0.739 & 5.8 & $0.076^{*}$ \\
\hline Moquegua & $\mathrm{F}(3)$ & $\mathrm{F}(4)$ & 0.679 & 0.719 & 3.0 & 0.069 \\
\hline Tacna & $\mathrm{F}(3)$ & $\mathrm{F}(7)$ & 0.682 & 0.609 & 3.5 & $-0.159 *$ \\
\hline Putre & $\mathrm{B}(6)$ & $\mathrm{B}(11), \mathrm{F}(6)$ & 0.713 & 0.736 & 4.9 & 0.033 \\
\hline
\end{tabular}

Localities ordered from north to south, type of sample (B indicates blood, D dead animals and $\mathrm{F}$ faecal), number of samples successfully genotyped for microsatellites and sequenced for their mtDNA and microsatellites is given. Reported values correspond to population mean estimates of expected heterozygosity (He), observed heterozygosity (Ho), average number of alleles per locus (ANAPL) and inbreeding coefficient $\left(F_{\text {IS }}\right)$. All samples sequenced for the mtDNA were also genotyped with microsatellites except those marked with ${ }^{\&}$. Significant $F_{\text {IS }}$ are marked with * small population size; (2) the higher specialisation and lower vagility of vicuñas has rendered its populations more differentiated than for the highly mobile guanaco, reflecting ecological constraints for vicuñas. These hypotheses, while of intrinsic value for attaining and supporting basic information on the biology of the species, are also expected to provide management-relevant information for the conservation of these threatened populations in the northern part of their range.

\section{Materials and methods}

Three hundred and seventy-eight northern vicuña ( $V . v$. mensalis) samples were collected between 1994 and 2009 from 13 populations in Peru and two in northern Chile (Lauca and Surire) (Figure 1 and Table 1). Samples comprised skin $(n=76)$ and blood $(n=302)$. Eighty-three samples of northern guanaco L. g. cacsilensis were collected from six Peruvian populations and Putre in Chile between April and December 2004. Samples comprised blood ( $n=$ $21)$ and faeces $(n=62)$ (Table 1). For faecal samples, pellets were collected from individuals observed defecating to avoid contamination between pellets from different individuals and to ensure the collected pellets were fresh. The faecal samples were preserved in $30 \mathrm{ml}$ of absolute ethanol. GPS coordinates were recorded for each sample. Total genomic DNA was isolated from blood and skin samples using a standard phenol chloroform extraction method following digestion with proteinase $\mathrm{K}$ (Bruford et al. 1998). DNA was precipitated in $100 \%$ ethanol and resuspended in $50 \mu \mathrm{l}$ TE buffer $(10 \mathrm{mM}$ Tris- $\mathrm{HCl}, 1 \mathrm{mM}$ EDTA, $\mathrm{pH}$ 8.0) prior to analysis. For the faecal samples, one pellet was used to extract DNA using the Qiagen DNA Stool Mini Kit following the manufacturer's instructions. 


\section{Mitochondrial analysis}

Vicuña mitochondrial control region molecular methods and analysis are described in detail in Marín et al. (2007). A fragment of up to $514 \mathrm{bp}$ of the left domain of the mitochondrial DNA (mtDNA) control region was amplified from 1 to 14 guanaco individuals per population using the primers Loop7G, LthrArtio, L362, H15998, H15063 and H493 (Marín 2004) in combination to produce short overlapping fragments.

Faecal DNA was amplified in a $10 \mu \mathrm{l}$ reaction volume containing $0.2 \mu \mathrm{M}$ each primer, $1 \mu \mathrm{l}$ BSA $(10 \mu \mathrm{g} / \mu \mathrm{l}), 3.5 \mu \mathrm{l}$ Qiagen PCR Multiplex Kit, $0.5 \mu \mathrm{l} \mathrm{H}_{2} \mathrm{O}$ and $4 \mu \mathrm{l}$ DNA. Thermocycling conditions were $95^{\circ} \mathrm{C}(15 \mathrm{~min})$, followed by 45 cycles of $94^{\circ} \mathrm{C}(30 \mathrm{~s})$, annealing temperature according to the set of primers used $(90 \mathrm{~s}), 72^{\circ} \mathrm{C}(60 \mathrm{~s})$ and a final extension step at $72{ }^{\circ} \mathrm{C}(10 \mathrm{~min})$. A negative control was included in each reaction. Fragments were sequenced in both directions using the BigDye ${ }^{\circledR}$ Terminator chemistry on an ABI3130 semi-automated DNA analyser. Sequences were aligned and edited manually using the programme SEQUENCHER v.3.1.2 (Gencodes Corp.). These data were complemented with vicuña mtDNA from wild populations in Peru and Northern Chile previously reported by Marín et al. (2007).

Genetic variation within populations was assessed using haplotype $(h)$ and nucleotide diversity $(\pi)$ estimated with ARLEQUIN 3.5.1.2 (Excoffier and Lischer 2010). This software was also used to carry out an analysis of molecular variance (AMOVA) on alternative population groupings in each subspecies. The relationships between haplotypes were estimated with the statistical parsimony approach implemented in TCS v1.21 (Clement et al. 2000). The demographic history of northern guanaco and vicuña was studied using the coalescent-based neutrality estimators Fu's $F_{\mathrm{S}}$ and Tajima's $D$ using ARLEQUIN, and FLUCTUATE 1.4 (Kuhner et al. 1998). The scaled effective population size parameter theta (Watterson 1975) was estimated in DnaSP 3.0 (Rozas et al. 2003) and used as starting parameter for the MCMC iterations in FLUCTUATE 1.4 to estimate the maximum likelihood estimates for $\theta$, together with the population growth parameter $g$. Parameter estimation was stabilised by conducting ten short MCMC chains of 4000 steps each and five long chains of 400,000 steps each, with a sampling increment of 20. Three independent runs were conducted. Since these estimates can be biased upwards, we adopted the approach of Lessa et al. (2003) in which population growth estimates were only recorded as significant if $g>3 \mathrm{SD}(g)$.

\section{Microsatellite analysis}

Populations were genotyped at 11 (vicuña) or 16 microsatellite loci (guanaco) using the markers YWLL08,
YWLL29, YWLL36, YWLL38, YWLL40, YWLL43, YWLL44, YWLL46 (Lang et al. 1996), LCA5, LCA19 and LCA22 for both species plus LCA23, LCA65, LCA82 (Penedo et al. 1998), LGU68 and LGU49 for guanaco only (Sarno et al. 2000). Amplification was carried out using the QIAGEN $^{\circledR}$ PCR multiplex kit in $10 \mu$ reaction volume containing $0.2 \mu \mathrm{M}$ each primer, $5 \mu \mathrm{l}$ PCR multiplex kit, $2 \mu \mathrm{l}$ $\mathrm{H}_{2} \mathrm{O}$ and $2 \mu \mathrm{l}$ DNA. The cycling profile used an initial denaturation step at $95^{\circ} \mathrm{C}(15 \mathrm{~min})$, followed by $25-45$ cycles of $94{ }^{\circ} \mathrm{C}(30 \mathrm{~s}), 59^{\circ} \mathrm{C}(90 \mathrm{~s}), 72^{\circ} \mathrm{C}(60 \mathrm{~s})$ and a final extension step at $60^{\circ} \mathrm{C}(30 \mathrm{~min})$. PCR products were run with an internal ROX350 size standard on an ABI3130 semi-automated DNA analyser and scored using the GENESCAN 3.7 and GENOTYPER 3.6 software. Each plate included an allelic ladder that acted as a positive control to allow consistent scoring of loci between plates. For faecal samples, each reaction was repeated three times for reproducible heterozygotes and up to seven times for homozygotes and samples exhibiting allelic dropout or false alleles following Taberlet et al. (1996). Consensus genotypes were constructed from the combined results. These data were complemented with data for two guanaco populations (Hua and $\mathrm{Pu}$ ) previously reported by Marín et al. (2013).

We identified multiple faecal samples from the same individual by searching for matching microsatellite genotypes using the Excel Microsatellite Toolkit (Park 2001), and eliminated one sample of a pair if it showed more than $85 \%$ overlap. The presence of null alleles was assessed with Micro-Checker version 2.2.3 (van Oosterhout et al. 2004) and STRUCTURE analysis (see below). Summary statistics of genetic variation (e.g., average number of alleles per locus, $H_{\mathrm{E}}$ ) and the $F_{\mathrm{ST}}$ were calculated with MSA (Dieringer and Schlötterer 2003) and the inbreeding coefficient with GENETIX v4.03 (Belkhir et al. 1996-). Population structure and individual-based assignment was assessed by Bayesian clustering using STRUCTURE (Pritchard et al. 2000) without using sampling locations as prior and using the admixture model including correlated allele frequencies with 100,000 steps as burn-in and 1 million steps for data collection. STRUCTURE was run ten times for values of the number of clusters $(K)$ from 1 to 9, and Evanno's method was used to identify the most likely $K$ value (Evanno et al. 2005). The average pairwise similarity $(H)$ of runs was assessed using the greedy algorithm in CLUMPP v.1.1.2 (Jakobsson and Rosenberg 2007) $(H=$ $0.78480676-0.9979564,10,000$ random input orders and 100 repeats). The partition of genetic variation for each individual across values of $K=2,3$ and 4 were visualised with DISTRUCT (Rosenberg 2004). We examined the effects of including loci with null alleles (as identified by Micro-Checker) on these results by running STRUCTURE including and excluding them for both species (not shown). 
Table 2 Summary of nucleotide $(\pi)$ and haplotype $(h)$ diversity, population growth parameters $\Theta_{\mathrm{w}}$ (Watterson 1975 ), $g$, Fu's $F_{s}$ and Tajima's $D$ for mtDNA control region sequences

\begin{tabular}{llllllll}
\hline Population groups & $h \pm \mathrm{SD}$ & $\pi \pm \mathrm{SD}$ & $\Theta \mathrm{w} \pm \mathrm{SD}$ & $\Theta \mathrm{g}=\mathrm{var} \pm \mathrm{SD}$ & $g \pm S D$ & $F_{\mathrm{s}}$ \\
\hline All Guanaco populations & $0.934 \pm 0.01$ & $0.017 \pm 0.01$ & $0.014 \pm 0.01$ & $0.131 \pm 0.04$ & $495.16 \pm 100$ & -2.2097 & 1.060 \\
Northern Guanaco & $0.884 \pm 0.04$ & $0.015 \pm 0.01$ & $0.013 \pm 0.01$ & $0.076 \pm 0.03$ & $378.48 \pm 96$ & -0.208 & 1.216 \\
Southern Guanaco & $0.871 \pm 0.05$ & $0.013 \pm 0.01$ & $0.017 \pm 0.01$ & $0.012 \pm 0.05$ & $467.18 \pm 106$ & -1.3570 & -0.187 \\
All vicuña populations & $0.775 \pm 0.03$ & $0.009 \pm 0.01$ & $0.019 \pm 0.01$ & $0.045 \pm 0.01$ & $173.93 \pm 55$ & -2.3944 & -0.535 \\
Northern vicuña & $0.555 \pm 0.06$ & $0.006 \pm 0.004$ & $0.009 \pm 0.01$ & $0.025 \pm 0.01$ & $539.76 \pm 216$ & 0.7464 & 0.540 \\
Southern vicuña & $0.868 \pm 0.02$ & $0.012 \pm 0.01$ & $0.019 \pm 0.01$ & $0.038 \pm 0.01$ & $138.37 \pm 52$ & -0.8181 & -0.137 \\
\hline
\end{tabular}

SD is the standard deviation. $F_{\mathrm{s}}$ and Tajima's $D$ are not significant. $\Theta_{\mathrm{w}}$ (Watterson 1975) was used to estimate $\Theta_{\mathrm{g}=0}$ and to give an initial value for $g$ (Kuhner et al. 1998). These values were then used to estimate $\Theta_{\mathrm{g}=\mathrm{var}}$ and $g \pm \mathrm{SD}$, calculated from the two-dimensional likelihood curve of the joint estimates of $\Theta_{\mathrm{g}=\mathrm{var}}$ and $g$

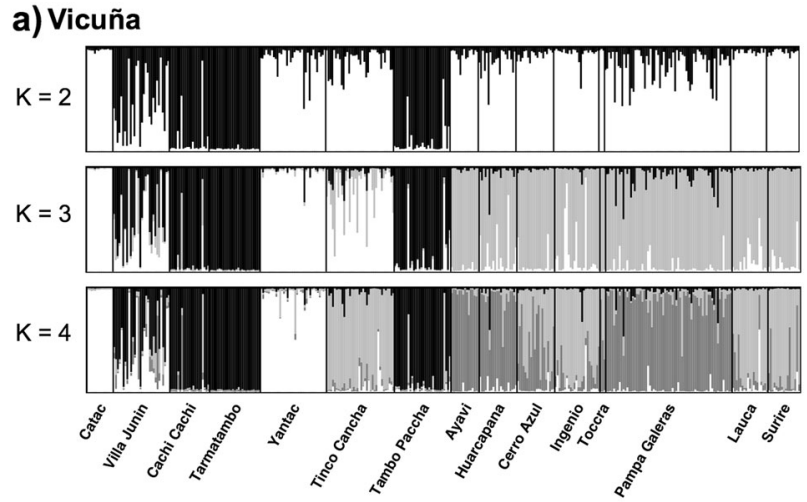

\section{b) Guanaco}

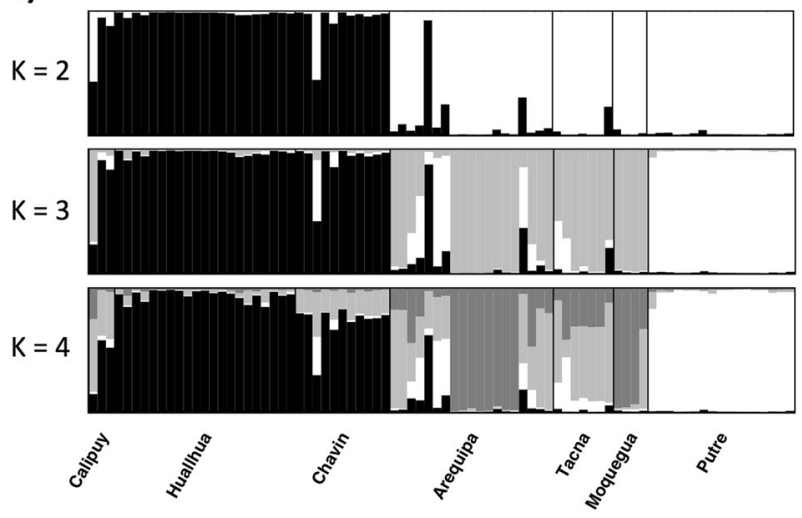

Fig. 2 Population structure and individual assignment of a vicuña and b guanaco populations, assessed by Bayesian clustering of microsatellite genotypes using STRUCTURE for $K=2,3$ and 4

Tests for Hardy-Weinberg equilibrium (H-W) for each locus in each sampling locality were implemented using Genepop v. 4.6 (Rousset 2008). The $p$ values were adjusted using the Benjamin-Yekutieli false discovery (FDR) approach (Benjamin and Yekutieli 2001) following Narum (2006).

Recent migration rates among sampling locations were assessed using BAYESASS v.1.3 (Wilson and Rannala 2003), an approach that does not assume $\mathrm{H}-\mathrm{W}$ equilibrium within populations. We set delta values for allele frequencies at 0.3 (maximum change between iterations), inbreeding coefficients at 0.30 and immigration rates at 0.18 , so that acceptance rates for changes in these parameters fell between 40 and 60\% (Wilson and Rannala 2003). BAYESASS was run three times with different random seeds to check for results convergence, with 2 million steps as burn-in and 6 million steps of data collection.

We used MSVAR to estimate the recent effective population size $\left(N_{0}\right)$, the ancestral effective population size $\left(N_{1}\right)$, and the time $(t)$ at which the effective population size may have changed from $N_{1}$ to $N_{0}$ using MSVAR v1.3 (Storz and Beaumont 2002). Three independent runs of MSVAR were carried out including wide prior distributions of the model parameters and accounting for the possibility that the populations remained stable over time, that there was a bottleneck, or a population expansion (Table S3). MSVAR was run for a total of 400 million iterations discarding the initial 20\% of the MCMC steps as burn-in. The independent runs were used to estimate the mode of the posterior distributions of each parameter $\left(N_{0}, N_{1}\right.$ and $\left.t\right)$ and their corresponding $90 \%$ highest posterior density interval. A generation length of 3 years (Frankin 1983) was used to rescale the $t$ parameter in years. Convergence of the runs was estimated with the Gelman and Rubin's diagnostic using the CODA library (Plummer et al. 2006) in $\mathrm{R}$ ( $\mathrm{R}$ Development Core Team 2009).

\section{Results}

\section{Mitochondrial analysis}

A final sequence alignment of $327 \mathrm{bp}$ mtDNA control region was obtained for 139 vicuñas and 50 guanacos after trimming. Seventeen haplotypes were detected in each species, with the vicuña haplotypes defined by 21 variable sites (Genbank accessions JQ754672-JQ754688), and the guanaco haplotypes defined by 20 variable sites (Genbank 
accessions JQ754689-JQ754705). Haplotype diversity was moderate to high for both species $(0.775 \pm 0.029$ for vicuña and $0.934 \pm 0.010$ for guanaco, Table 2$)$, whereas, nucleotide diversity was low $(0.009 \pm 0.006$ for vicuña $0.017 \pm$ 0.009 for guanaco). AMOVA revealed that for both species, the highest variance component was found within localities (explaining $76 \%$ of the variation for guanaco and $77 \%$ for vicuña, $p<0.001$ ) although variance among localities was also significant. We further explored the partitioning of molecular variance for both species using the northern and southern population clusters identified by STRUCTURE with the microsatellite data (see below), i.e., three groups for vicuña and two groups for guanaco (see Fig. 2a, b). While the north-south variance component was essentially zero and non-significant for vicuña, for the guanaco it explained $21.86 \%$ of the variance, which was highly significant, as were both the among-population and withingroup $(8.77 \%)$, and the within-population variance components $(69.37 \%)$.

The minimum spanning networks (Fig. 3a, b) show a single-dominant haplotype occurred in most vicuña samples; however, several other common haplotypes were also observed from which related sequences were separated by one or two mutational steps. Furthermore, four divergent haplotypes separated by a minimum of seven mutations from the nearest haplotype were also observed, all of which occurred in the two Chilean populations. In contrast, the guanaco network featured less haplotype sharing among sampling localities, with several haplotypes occurring at intermediate to high frequency. Consistent with a demographically stable population history with multiple haplotypes at medium-high frequencies, $\pi$ and $\Theta w$ were comparable in each grouping (Table 2), and neutrality tests (Fu's $F_{\mathrm{s}}$ and Tajima's $D$ ) were not significant. Nevertheless, the coalescent-based analysis of population expansion using FLUCTUATE supported a demographic expansion with large positive $g$ parameters $(g>3 \mathrm{SD}(g)$ in both the guanaco and vicuña populations, $(495.159 \pm 100.462$ and $173.930 \pm$ 55.814, respectively) (Table 2).

\section{Microsatellite analysis}

Among the 103 guanaco multilocus microsatellite genotypes obtained from faeces, we identified two as corresponding to the same individual. The null alleles test using Microchecker identified five loci with null alleles in guanaco (YWLL38, YWLL43, YWLL44, YWLL46 and LCA22). However, summary diversity statistics of (i.e., expected heterozygosity, allelic richness and inbreeding coefficient) and divergence (i.e., $F_{\mathrm{ST}}$ ) were not significantly different when excluding these loci from the analyses (Welch $t$-tests $p$ value $>0.05$ ), and an analysis of population structure including and excluding these loci rendered the same results (Supporting Material Figure S1), thus, all loci were retained for analyses. The final guanaco data set had a total of 145 alleles detected across 16 loci, with the number of alleles per locus varying from 4 to 17 . H-W equilibrium tests were significant for the locus LCA23 in AQP (B-Y FDR corrected $p$ value $<0.05$ ). In vicuñas no null alleles were detected, and no duplicated individuals were detected among the 377 genotyped. A total of 128 alleles at 11 loci were observed, with the number of alleles per locus ranging from 3 to 31 . For vicuña after B-Y FDR $p$ values correction, three loci were not in $\mathrm{H}-\mathrm{W}$ equilibrium in Yantac (YWLL40, YWLL08 and YWLL38), one in Cerro Azul (LCA22), one in Tambo Paccha (YWLL38), while the locus YWLL43 was not in H-W for Villa Junin, Ingenio, Lauca and Surire. Excluding these loci from the populations where they were not in $\mathrm{H}-\mathrm{W}$ equilibrium did not result in a significant difference in summary statistics of genetic diversity (e.g., expected heterozygosity, $F_{\text {IS }}$ ) when compared to including them (Welch $t$-test all $p$ values $>0.45$ ). Due to the presence of multiple loci out of $\mathrm{H}-\mathrm{W}$ in Yantac, we looked for evidence of Wahlund effect in that population using the software STRUCTURE and a data set including and another excluding these loci. We found that with either of these data sets, all animals were grouped in one cluster with a posterior probability of $99.9 \%$ over alternative clustering solutions, indicating that these loci do not contribute substantially to changing the demographic history signal, and thus we kept them for further analyses. Guanacos showed a significantly higher-expected heterozygosity than vicuñas $\left(H_{\mathrm{e}} \sim 0.58\right.$ and $H_{\mathrm{e}} \sim 0.48$, respectively; Welch's $t$-test $p$ value $=0.017$; Table 1), whereas both the per locus $F_{\text {IS }}$ and $F_{\text {ST }}$ values were not significantly different between the two species (Table 1 and Table S4a, b).

Bayesian clustering showed the highest change in likelihood (delta) between $K=1$ and $K=2$ for both species with no consistent increase in likelihood value above $K=3$ or $K=4$ (not shown). Figure $2 \mathrm{a}$, b shows the bar plots for vicuña and guanaco for $K=2-4$, respectively. At $K=2$ for vicuña, one cluster corresponds to samples broadly distributed throughout the species range (mean ancestry fraction $(Q)=0.91$ and ranging between 0.813 and 971), while the other cluster corresponds to a group of three northeastern populations (Cachi Cachi, Tarmatambo and Tambo Paccha; mean $Q=0.925$, ranging between 0.890 and 0.976). The population of Villa Junin shows widespread admixture between the two clusters (mean cluster 2 ancestry fraction $=0.562)$ consistent with its intermediate geographical position. At $K=3$, the north-eastern cluster remained unaltered, and the widespread cluster divided into two, with one group comprising the populations of the north-west cordillera (Catac, Yantac and Tinco Cancha) (mean $Q=0.899$, ranging between 0.763 and 0.980 ), and a second group comprising the central and southern 
Fig. 3 Minimum spanning network of haplotypes for a vicuña and $\mathbf{b}$ guanaco populations in Peru and Chile. The size of each haplotype is proportional to its frequency (e.g., the haplotype with the number 17 in both networks corresponds to one individual). Dashed lines indicate alternative connections between haplotypes

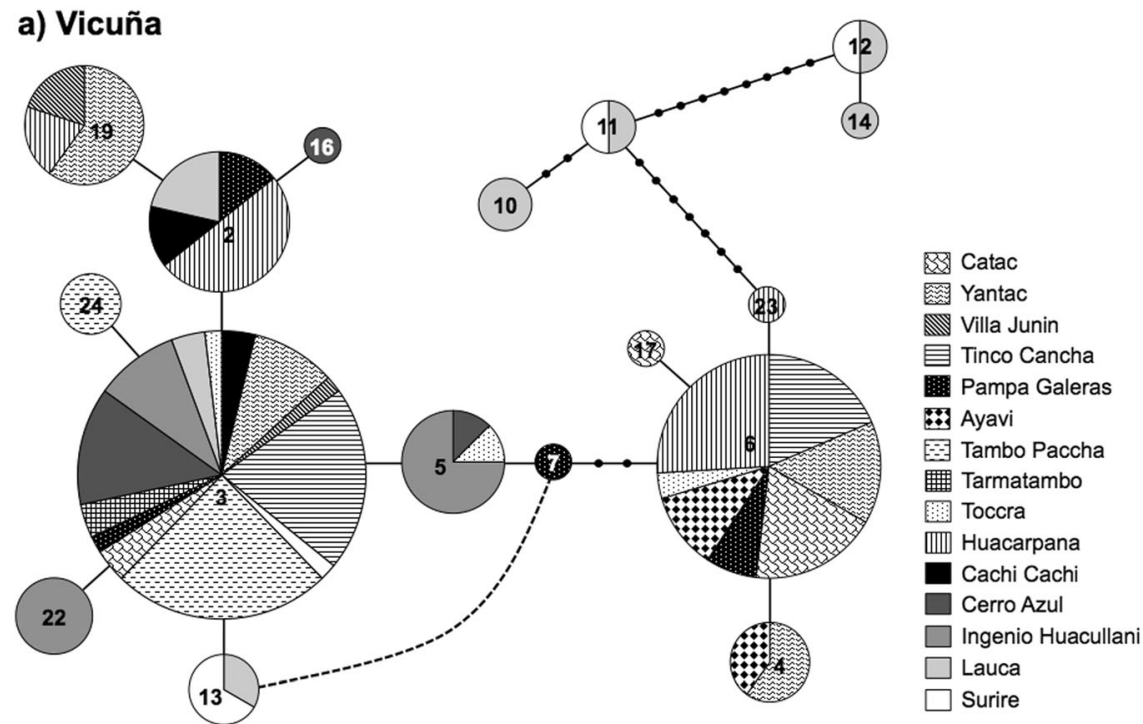

b) Guanaco

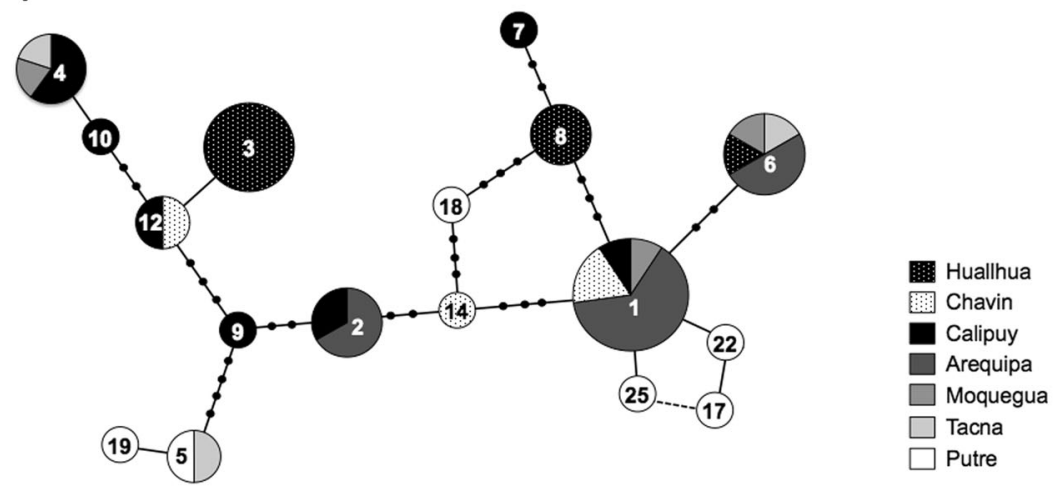

populations ranging from Ayavi to southernmost Putre (mean $Q=0.889$, ranging between 0.801 and 0.978). Again, Villa Junin, showed admixture with a mean northwestern cordillera ancestry of $Q \sim 0.470$ and a mean northeastern ancestry of $Q \sim 0.430$. At $K=4$, the central/southern cluster divided into two, with the central Peruvian populations of Ayavi, Huarcapana and Pampa Galeras clustering together, and the southern Peruvian/northern Chilean populations (Ingenio Huacullani, Toccra, Lauca and Surire), with the Cerro Azul population showing admixture between these two clusters. The Tinco Cancha population, previously assigned to the north-west cordillera cluster, groups with the southern Peruvian/northern Chilean populations. Villa Junin still shows evidence of admixture between the north-western cordillera and north-eastern cordillera.

For the guanaco, at $K=2$ the samples divide into a cluster of northern samples (Calipuy, Chavin and Huallhua) (mean $Q=0.891$, ranging between 0.758 and 0.988 ) and of southern samples (Arequipa, Moquegua, Tacna and Putre) (mean $Q=0.955$, ranging between 0.895 and 0.988 ; Fig. 2b). At $K=3$, the southern cluster divides in two clusters, a southern Peruvian group comprised of samples form Arequipa, Tacna and Moquegua (mean $Q=0.894$, ranging between 0.724 and 0.978), and a Chilean cluster comprised of samples from Putre $(Q=0.981)$. The Arequipa samples varied in their ancestry coefficients displaying more of a southern Peruvian background but with various levels of admixture with the other clusters. Arequipa Department covers a very large geographic area and the subdivision seen here represented the geographic segregation of sampling locations. At $K=4$, the northern and Chilean clusters remain supported, while Arequipa subdivides into two groups with the samples for northern and central Arequipa (Salamanca and RNSAB) and Tacna clustering together, while the southern Arequipa group (Yarabamba) clustered with Moquegua, which, although a different political department, is geographically adjacent. The observed geographical pattern (North-South) found in both species could arise as a result of isolation by distance (IBD). For vicuña, this was not evident when testing for correlations between geographical distances and the rescaled divergence parameters $F_{\mathrm{ST}}$ (i.e., $F_{\mathrm{ST}} /\left(1-F_{\mathrm{ST}}\right)$; Mantel test between 15 
Fig. 4 Demographic analysis of vicuña and guanaco with MsVar. In each plot the posterior distributions of the current effective population size (top row), the ancestral effective population size (middle row) and the time of the bottleneck (bottom row) are shown for each of the three MsVar replicates for each locality analysed. The $x$ axis values are in $\log$ scale (e.g., 2 means $10^{2}$ )
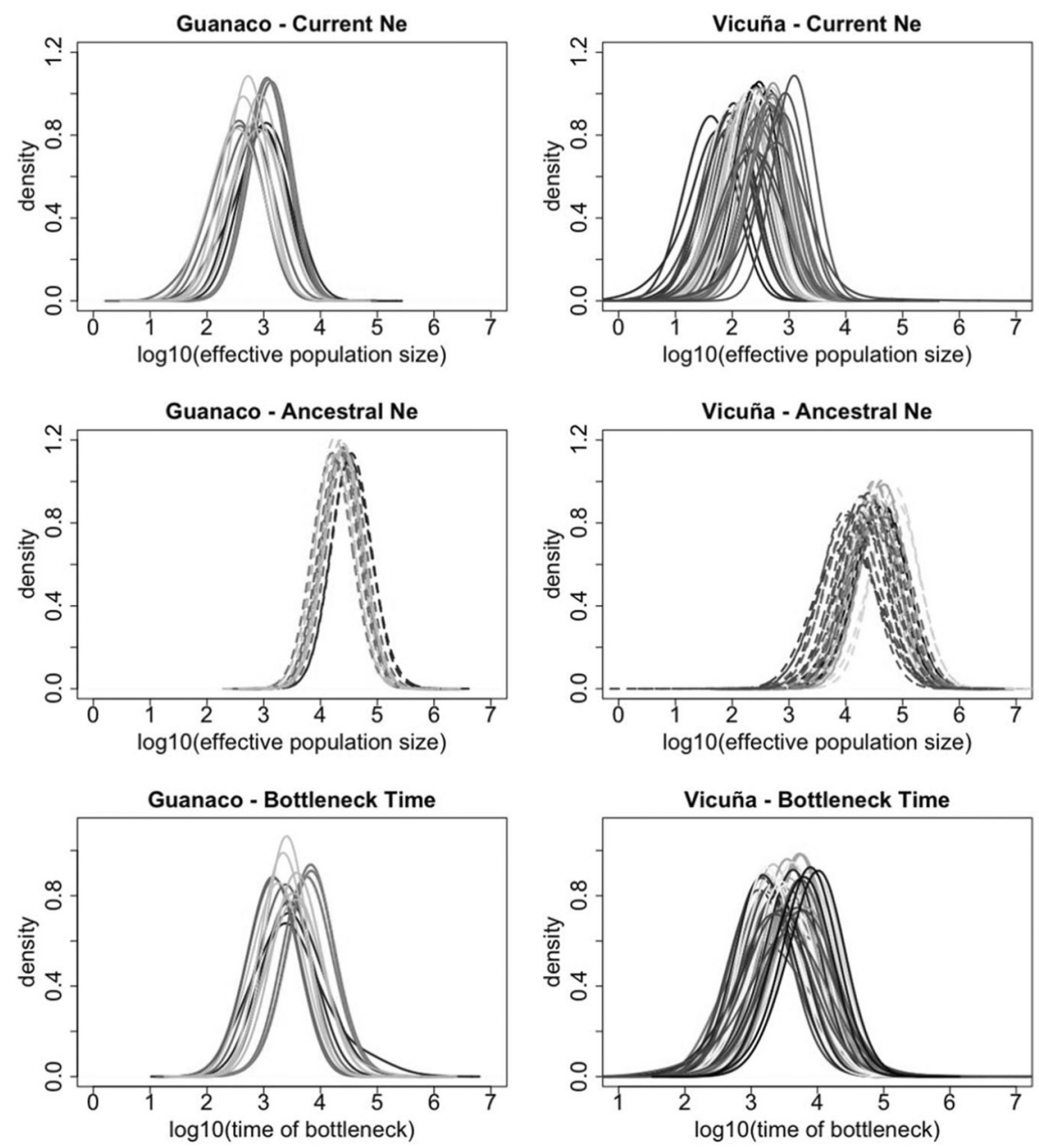

Table 3 Demographic inference using MsVar

\begin{tabular}{llll}
\hline Species & $N_{0}$ & $N_{\mathrm{t}}$ & Time of bottleneck \\
\hline Guanaco & $524(112-3424)$ & $19,766(6573-85,152)$ & $2063(442-21,028)$ \\
Vicuña & $208(38-1219)$ & $24,426(3938-166,929)$ & $3318(437-25,317)$ \\
\hline
\end{tabular}

Average estimates across sampling localities of the current effective population size $\left(N_{0}\right)$, the ancestral effective population size $\left(N_{t}\right)$ and the time of the bottleneck in years before the present. For each estimate, the $95 \%$ highest posterior density interval is provided in parenthesis localities $p$ value $>0.1$ ), while for the guanaco a significant correlation $\left(R^{2} \sim 0.43\right.$; Mantel test between seven localities $p$ value $<0.05$ ) was found, indicating that IBD plays a role in explaining the diversity in this species.

The posterior probabilities (Table S5 a, b) of recent migration between guanaco localities estimated using BAYESASS were generally low (less than or close to 5\%), except for Huallhua to Chavin (0.21), Moquegua to Arequipa (0.184) and Moquegua to Tacna (0.179). For vicuña, estimates were effectively zero except for Tambo Paccha to Cachi Cachi (0.267) and Tarmatambo (0.281), from Huarcapana to Catac (0.240), from Pampa Galeras to both Huarcapana (0.260) and Ayavi (0.243), and from Ingenio Huacullani to both Lauca (0.220) and Surire (0.2156).
Populations where high-posterior probabilities were recorded are all geographically proximate, with the exception of Catac and Huacarpana (vicuña).

Analyses of demographic history were carried out on the sampling localities with the exception of Calipuy (due to missing data). For each population, three MCMC runs under three different demographic models were tested and their convergence was assessed with the Gelman and Rubin's statistic (all results showed a Gelman and Rubin statistic lower than 1.2). MSVAR detected evidence for major effective population size declines in both species, consistent with current or recent small census sizes (Figure 4, Table 3 and Tables S6). Both species presented large ancestral effective population sizes in the order of $\sim 20,000$ 
individuals (with 95\% highest posterior density interval (HPD) $\sim 6500$ to $\sim 85,000$ in guanaco, and $\sim 4000$ to over 150,000 in vicuna; Table 3 ). The start of the bottleneck signature for guanaco was dated to $\sim 2000$ years before the present (YBP; HPD 400-21,000 YBP), with $\sim 3300$ YBP (HPD 400-25,000 YBP) inferred for vicuña. Following this event, the effective population size in guanaco reached 500 (HPD 100-3400) while the vicuña decreased even further to $\sim 200$ (HPD 38-1200; Table 3).

\section{Discussion}

This study presents the first comprehensive comparative analysis of genetic variation in the northern range of the vicuña and guanaco, covering Peru and northern Chile, contextualised with two hypotheses on the drivers of genetic variation and structure in these species. Our first hypothesis is based on very recent demographic trajectories and basic life history differences between these two closely related taxa. The Peruvian guanaco, which is currently at critically low numbers due to ongoing hunting was expected to have lower genetic diversity than the vicuña in the same region, which currently has census population sizes in Peru of 200,000 , having been reduced to less than 10,000 individuals during the 1970s. Second, we predicted that the sedentary and altiplano-restricted vicuña would show higher amongpopulation differentiation than the more vagile and generalist guanaco. We addressed these questions using markers that are potentially informative for very recent demographic processes (microsatellites) as well as events further back in the past (mtDNA). However, distinguishing the genetic signatures of ancient and modern events can be challenging in threatened species (e.g., Nichols and Beaumont 1996).

Mitochondrial DNA variation was remarkably similar for both species, with the same number of haplotypes identified and a similar number of substitutions. In general, haplotype diversity was relatively high and nucleotide diversity was relatively low, suggesting a demographic expansion in both species, although Tajima's D and Fu's F were not statistically significant albeit showing negative values. Nevertheless, these diversity patterns in combination with the large positive population growth parameter $(g)$ for both species suggest that an expansion may have occurred in the distant past. However, more recent demographic changes, as inferred using microsatellites, may have contributed to distorting the signature indicated by the neutrality test. For the vicuña, this is most likely to have coincided with the opening up of the wet altiplano due to increased precipitation associated with the last glacial maximum in the Andes 12,000-9000 YBP (Ammann et al. 2001) when vicuña populations are thought to have become extremely large (Marín et al. 2007; Wheeler 1995). However, for the guanaco, the inferred population expansion cannot be explained by habitat changes in elevational zones alone, because this species is an altitudinal generalist with a much wider distribution (Frankin 1983). This interpretation contrasts somewhat with that of Marín et al. (2008) who found no evidence of demographic expansion in $L$. g. cacsilensis, although their analysis was limited to the estimation of mismatch distributions which are known to be conservative and not always statistically powerful (Ramos-Onsins and Rozas 2002). Importantly, when the northern and southern populations of both species are considered separately, contrasting patterns were revealed. For the guanaco, southern populations appear to have expanded more than in the north, whereas for the vicuña the opposite is process could be inferred, reflecting differences in the post-glacial history along the Andean chain and its impact on the species inhabiting different refugia. The larger northern expansion in the vicuña detected here recapitulates the results of Marín et al. (2007) where vicuña populations north of the Dry Diagonal were inferred to have expanded more than those within it.

Further supporting the results of Marín et al. (2007), limited geographical structure was evident in northern vicuña based on mtDNA haplotype distribution. In contrast, a significant component of the molecular variance in guanaco could be explained by a north-south division. 'Northern' populations identified using microsatellite data (see below) were located $\sim 08^{\circ} 27^{\prime \prime} \mathrm{S}$ to $14^{\circ} 43^{\prime \prime} \mathrm{S}$, which was comparable with the distribution of 'northern' haplotypes, although these were not divided exclusively between this region and populations further south (Fig. 3b). Marín et al. (2008) inferred the potential presence of an isolation-bydistance structure in L. g. cacsilensis, and its inclusion in spatial analyses for the whole species was key for the identification of a significant (if weak) correlation between genetic and geographic distance across the entire South American range. We found, with an expanded data set, that guanacos in Peru and northern Chile show a similar pattern of genetic structure. Nevertheless, the north-south divide seen in the microsatellite data possibly alludes to a separate glacial or post-glacial expansion for northern and southern L. g. cacsilensis, followed by secondary contact, and (or) it may also reflect more recent population processes in comparison to mtDNA which reflect more ancient demography. Although the guanaco's current distribution is related to its utilisation of the pacific slopes of the Andes and the adjacent puna ecosystem of the western cordillera, there are no clear geographic divisions or barriers that might explain the separation of these populations. It is clear, however, that the guanaco's generalist strategy permits wide ranging utilisation of diverse habitats and the occupation of a variety of refugia in the face of climate change and possible anthropogenic pressure. 
Microsatellite analysis detected a significant difference in expected heterozygosity between the two species. However, this occurred in the opposite direction as our original prediction, with the guanaco possessing higher variation. It is possible that this result is confounded by the effects of ascertainment bias in microsatellite isolation (Hutter et al. 1998) since most of the markers used were isolated from llama (the domestic descendent of the guanaco; Lang et al. 1996; Penedo et al. 1998), and thus would be expected to be more variable in guanaco than in the more distantly related vicuña. Nevertheless, there was no significant difference in the number of alleles detected per species (which was higher for vicuña for seven out of the eleven loci in common) and it is not clear whether the camelids used to isolate the microsatellite markers were genetically pure llamas, since nuclear introgression of alpaca genetic material in domestic llamas occurs at a rate of $\sim 40 \%$ (Kadwell et al. 2001) and the alpaca was domesticated from the vicuña. These data therefore do not clearly support the hypothesis that recent demographic processes have substantially altered nuclear genetic diversity in these two species with respect to each other.

Our second hypothesis, that vicuña should exhibit greater genetic differentiation among populations than guanaco, also received equivocal support from the data. There was no significant difference in mean per locus $F_{\mathrm{ST}}$ for the two species, with vicuña values exceeding those of guanaco for four of the 11 loci in common (Table S2). Guanaco showed more negative $F_{\text {IS }}$ values than vicuña, and vicuña showed more localities with significantly positive $F_{\text {IS }}$ values, suggesting some outbreeding in guanacos and inbreeding in vicuñas. BayesASS posterior probabilities, however, suggest low recent migration in both species, although migration was inferred to be higher for guanaco, consistent with differences in behaviour and ecology, where guanacos are more attitudinally mobile and have higher home ranges. In both species, the best supported statistically STRUCTURE result suggested two groups, nonetheless, the highest number of clusters that clearly defined regional groupings in a biological and geographic context for vicuña was four, as opposed to two (or at most three) in the guanaco (Fig. 2a, b). Interestingly, both analyses identified a north-south division in population structure, although the boundary identified between these geographic clusters was found at different latitudes (between $14^{\circ} 43^{\prime \prime} \mathrm{S}$ and $15^{\circ} 39^{\prime \prime} \mathrm{S}$ for the guanaco and between $11^{\circ} 25^{\prime \prime} \mathrm{S}$ and $13^{\circ} 42^{\prime \prime} \mathrm{S}$ for vicuña). As stated above, while these clusters also partitioned a substantial component of the mitochondrial variance in the guanaco, this was not the case for the vicuña. The northsouth separation of vicuña corresponds approximately to the point where the western, central and eastern cordilleras join (Fig. 1, insert). North of this point vicuña were divided into two populations, one on the western and one on the central cordillera. To the south of the divide, a central Andean population was found across the western and central cordilleras, in turn separated from the southern populations roughly at the point where the central and eastern cordilleras join to form the Nudo de Vilcanota in Cusco. Beyond this point the vicuñas are found on the west central and eastern cordilleras forming an arc around Lake Titicaca and extending into northern Chile. In contrast, the guanaco is essentially restricted to the pacific slope from the coast to the adjacent heights of the western cordillera.

Pairwise $F_{\mathrm{ST}}$ values for microsatellites among localities were nearly all statistically significant for both species (range, $0.073-0.242$ in guanaco and $0.030-0.408$ in vicuña), with all the non-significant comparisons between guanaco localities and $9 / 11$ in vicuña involving localities with sample sizes of four individuals or less (Tables S4a, b). A negative correlation was found between expected heterozygosity and $F_{\mathrm{ST}}$ in vicuña $\left(r=-0.62, p\right.$ value $\left.\sim 1.1 \mathrm{e}^{-12}\right)$ and guanaco ( $r=-0.6, p$ value $\sim 0.0037$ ), suggesting that the $F_{\mathrm{ST}}$ values are probably elevated due to genetic drift in the localities analysed (Weeks et al. 2016). However, because these values can be influenced by a myriad of local, unknown demographic processes, we chose instead to focus on a Bayesian assessment of recent migration, since this demographic process is most likely to influence contemporary management of populations for conservation (e.g., Goossens et al. 2005). In agreement with pairwise $F_{\mathrm{ST}}$ data, most Bayesian posterior immigration probabilities were low (less than 5\%; Table S5 a, b), with three guanaco populations where recent immigration was inferred as highly likely, and five in vicuña. These populations, as expected, are geographically proximate and are within the same cluster inferred with STRUCTURE for each species. For vicuña, these migration events were inferred to have occurred within, and not between, the north-east, central and south Andean clusters, while for the guanaco the same scenario of migration between populations within clusters holds.

In contrast to the possible ancient expansion suggested by the mitochondrial DNA results, the demographic analyses using MSVAR consistently supported a recent bottleneck for both species (Fig. 4). Large ancestral effective population sizes could be inferred for both species $(\sim 20,000)$, reduced to 500 or less (current effective population size) through a bottleneck that took place $\sim 2000$ YBP (95\% HPD 400-21,000 YBP) for the guanaco, and 3300 YBP for the vicuña (95\% HPD 400-25,000 YBP). For the vicuña the estimated bottleneck took place longer ago than the population low registered in the 1970s of fewer than 5000 individuals, and from which the species has recently recovered to 200,000 or more individuals in Peru alone. This recent reduction in census population size may not have been severe enough to have affected the effective 
population size, and may not have resulted in a further loss of genetic variation, as has been shown for Guanacos on the Falkland Islands (Gonzalez et al. 2014).

The bottleneck results obtained with MSVAR were consistent across populations, therefore reducing the probability of identifying false bottlenecks (Chikhi et al. 2010; Peter et al. 2010). The modal estimate of the start of the bottleneck timing was between $\sim 2000$ and $~ 3000$ YBP, however, the $95 \%$ highest posterior density of these estimates spans between $\sim 400$ and $\sim 20,000$ YBP, covering a long period of time where dramatic changes on the South American landscape occurred. During this long timespan, South American megafaunal extinction occurred, probably prior to the arrival of humans (dated to $14,500 \mathrm{YBP}$ at Monte Verde, Chile; Dillehay 2009; Metcalf et al. 2016; Shockey et al. 2009), as well as multiple major temperature oscillations (Barnosky and Lindsey 2010; Kuentz et al. 2011). During the Middle Holocene, (7500-5000 YBP) different climatic dynamics dominated the highlands and western slopes of the Andes (Kuentz et al. 2011), where variation in altitude, longitude and latitude is also thought to have created a fluctuating patchwork of wet and dry environments. By 9000 years ago, human hunters were well established in the high Andes of Peru (Aldenderfer 1999), where evidence of a progression from generalised to specialised hunting (9000-6000 BP) on vicuña and guanaco (Wheeler et al. 1976) led to the onset of the domestication of the vicuña by 6000-5500 BP (Wheeler 1995) and subsequently of the guanaco, following a cool period that marks the divide between the earlier warmer Holocene, and the cooler late Holocene (Thompson et al. 2006). Following this period, South America's human population appears to have entered a renewed exponential phase of demographic growth lasting until $\sim 2000$ years ago with the total population having reached as much as 1,000,000 individuals (Goldberg et al. 2016). Lastly, the lower boundary of the 95\% highest posterior interval reaches near 400 years ago, after the start of the European conquest of South America. This period was characterised by a dramatic reduction in the native human population size, as well as in the population size of South American Camelids (Kadwell et al. 2001; Wheeler 2012b; Wheeler et al. 1995). While identifying the driver(s) of the bottleneck observed in guanaco and vicuña in light of all these changes is difficult, it is likely that the human demographic expansion that took place near the time of the onset of camelid domestication may be a major factor. The data presented in this study are also relevant to the genetic management of Peru and northern Chile's wild camelid genetic resources, where some populations (for example the guanaco in southern Peru) are under imminent threat of extinction. Identification of management units for conservation is therefore desirable and the use of these data, complemented with additional sampled localities and genomic analysis, should therefore assist in this process, provided the interacting factors of recent anthropogenic demographic declines within populations which induce genetic drift and high population differentiation, longstanding natural barriers to gene-flow among populations and human mediated translocations and hunting are properly accounted for.

\section{Data accessibility}

DNA sequences are accessible though GenBank: JQ754672-JQ754705. Microsatellite Data available from Dryad: https://doi.org/10.5061/dryad.g8d77ft.

Acknowledgements Darwin Initiative for the Survival of Species (UK) grants 162/06/126 and 162/12/022; Asociación Ancash (Peru); European Commission INCO-DC ICA4-2000-10229-MACS; FINCyT (Peru) grant 006-FINCyT-PIBAP-2007; COLP (Peru) grants PLNG-EV-9832, PLNG-EV-09012; CONICYT PhD studentship, and FONDECYT (Chile) grants 1140785 and 3050046. Peruvian samples were collected under permits from CONACS (28 Sept. 1994, 15 June 1997), INRENA (011-c/c-2004-INRENA-IANP; 012-c/c-2004INRENA-IANP; 016-c/c-2004-INRENA-IFFS-DCB; 016-c/c-2004INRENA-IFFS-DCB; 021-c/c-2004-INRENA-IFFS-DCB; 026-c/c2005-INRENA-IANP) and DGFFS (109-2009-AG-DGFFSDGEFFS). Chilean samples were collected under the permit 447 of the Servicio Agricola y Ganadero SAG, and permit 6/02/2002 of the Corporación Nacional Forestal (CONAF). Peruvian samples were exported to the UK under CITES permit numbers 00658, 6282, 4222, 6007, 5971, 0005177, 0005178, 023355, 022967 and 022920 and import permit numbers 269602/01 and 262547/02. Chilean samples were exported to the UK under CITES permit numbers 0007 and 0005176 and import permit numbers $269658 / 01$ and $262547 / 02$. The authors would like to thank the anonymous reviewers that contributed to improve our manuscript.

Author contributions Authors contributed the following to this manuscript: project leaders (M.W.B., J.C.W. and R.R.), fieldwork (M. K., M.F., J.C.M. and D.H.), laboratory work (C.S.C., M.K., M.F., J.C. M. and L.M.), data analysis (P.O-.T.W., C.S.C., Y.H., J.C.M. and M. W.B.), produced the manuscript (P.O.T.W., C.S.C., J.C.W., and M.W. B.).

Conflict of interest The authors declare that they have no conflict of interest.

\section{References}

Aldenderfer M (1999) The Pleistocene/Holocene transition in Peru and its effects upon human use of the landscape. Quat Int 53-54:11-19

Ammann C, Jenny B, Kammer K, Messerli B (2001) Late quaternary glacier response to humidity changes in the arid Andes of Chile (18-29옹. Palaeogeogr Palaeoclimatol Palaeoecol 172:313-326

Anello M, Daverio MS, Romero SR, Rigalt F, Silbestro MB, VidalRioja L et al (2016) Genetic diversity and conservation status of managed vicuna (Vicugna vicugna) populations in Argentina. Genetica 144(1):85-97

Baldi R, Acebedes P, Cuéllar E, Funes M, Hoces D, Puig S et al (2016) Lama guanicoe. The IUCN Red List of Threatened Species. e.T11186A18540211.ISSN 2307-8235 
Barnosky A, Lindsey E (2010) Timing of Quaternary megafaunal extinction in South America in relation to human arrival and climate change. Quat Int 217:10-29

Belkhir K, Borsa P, Chikhi L, Raufaste N, Bonhomme F (1996) Laboratoire génome, populations, interactions, CNRS UMR 5000. Université de Montpellier II, Montpellier, 2004

Benjamin Y, Yekutieli D (2001) The control of the false discovery rate in multiple testing under dependency. Ann Stat 29:1165-1188

Brack A (1980) Conservación de la vicuña en el Peru. Fondo Editorial del Ministerio de Agricultura y Alimentacion, Lima, (Peru), 33pp.

Bruford M, Hanotte O, Burke T (1998) Multi- and single locus DNA fingerprinting. IRL Press, Oxford

Bustamante A, Zambelli A, De Lamo D, von Thungen J, Vidal-Rioja A (2002) Genetic variability of guanaco and llama populations in Argentina. Small Rumin Res 47:97-101

Chikhi L, Sousa VC, Luisi P, Goossens B, Beaumont MA (2010) The confounding effects of population structure, genetic diversity and the sampling scheme on the detection and quantification of population size changes. Genetics 186(3):983-995

Clement M, Posada D, Crandall KA (2000) TCS: a computer program to estimate gene genealogies. Mol Ecol 9(10):1657-1659

Dieringer D, Schlötterer C (2003) Microsatellite analyser (MSA): a platform independent analysis tool for large microsatellite data sets. Mol Ecol Notes 3:167-169

Dillehay TD (2009) Probing deeper into first American studies. Proc Natl Acad Sci USA 106(4):971-978

Dodd C, Rodriguez J, Hoces D, Rosadio R, Wheeler J, Bruford M (2006) Genetic diversity and management implications for vicuña populations in Peru. In: Gerkin M, Renieri C (eds) South American Camelid Research, Vol 1. Wageningen Academic Publishers, Wageningen, p 87-96

Evanno G, Regnaut S, Goudet J (2005) Detecting the number of clusters of individuals using the software STRUCTURE: a simulation study. Mol Ecol 14(8):2611-2620

Excoffier L, Lischer HE (2010) Arlequin suite ver 3.5: a new series of programs to perform population genetics analyses under Linux and Windows. Mol Ecol Resour 10(3):564-567

Frankin W (1983) Contrasting socioecologies of South America's wild camelids: the vicuña and the guanaco. In: Eisenberg J, Kleiman D (eds) Advances in the study of animal behaviour, American Society of Mammalogists, Allen Press, Lawrence, Kansas, USA. pp 573-629.

Goldberg A, Mychajliw AM, Hadly EA (2016) Post-invasion demography of prehistoric humans in South America. Nature 532 (7598):232-235

Gonzalez BA, Orozco-Terwengel P, von Borries R, Johnson WE, Franklin WL, Marín JC (2014) Maintenance of genetic diversity in an introduced island population of guanacos after seven decades and two severe demographic bottlenecks: implications for camelid conservation. PLoS ONE 9(3):e91714

Goossens B, Chikhi L, Jalil MF, Ancrenaz M, Lackman-Ancrenaz I, Mohamed M et al. (2005) Patterns of genetic diversity and migration in increasingly fragmented and declining orang-utan (Pongo pygmaeus) populations from Sabah, Malaysia. Mol Ecol 14(2):441-456

Grimwood I (1969) Notes on the distribution and status of some Peruvian mammals. American Committee for Wildlife Protection. Zoological Society Special Publication, New York, Vol 21

Hamilton G, Stoneking M, Excoffier L (2005) Molecular analysis reveals tighter social regulation of immigration in patrilocal populations than in matrilocal populations. Proc Natl Acad Sci USA 102(21):7476-7480

Hoces D (2005) Guanaco: el camélido injustamente olvidado. Rev Agric 300:140-143
Hutter CM, Schug MD, Aquadro CF (1998) Microsatellite variation in Drosophila melanogaster and Drosophila simulans: a reciprocal test of the ascertainment bias hypothesis. Mol Biol Evol 15 (12):1620-1636

INEI (2013) Resultados difinitivos: IV censo nacional agropecuario 2012. http://sinia.minam.gob.pe/index.php?accion= verElemento\&idElementoInformacion $=1378$

IUCN (2010) The IUCN red list of threatened species. http:// iucnredlist.org/apps/redlist/details/22956/0

Jakobsson M, Rosenberg NA (2007) CLUMPP: a cluster matching and permutation program for dealing with label switching and multimodality in analysis of population structure. Bioinformatics 23 (14):1801-1806

Kadwell M, Fernandez M, Stanley HF, Baldi R, Wheeler JC, Rosadio $\mathrm{R}$ et al. (2001) Genetic analysis reveals the wild ancestors of the llama and the alpaca. Proc Biol Sci 268(1485):2575-2584

Kuentz A, Ledlru M, Thouret J (2011) Environmental changes in the highlands of the western Andean Cordillera, southern Peru, during the Holocene. Holocene 22(11):1215-1226

Kuhner MK, Yamato J, Felsenstein J (1998) Maximum likelihood estimation of population growth rates based on the coalescent. Genetics 149(1):429-434

Kunkel K, Atwood T, Ruth T, Pletscher D, Hornocker M (2013) Assessing wolves and cougars as conservation surrogates. Anim Conserv 16:32-40

Lang K, Wang Y, Plante Y (1996) Fifteen polymorphic dinucleotide microsatellites in llamas and alpacas. Anim Genet 27:293

Lessa EP, Cook JA, Patton JL (2003) Genetic footprints of demographic expansion in North America, but not Amazonia, during the Late Quaternary. Proc Natl Acad Sci USA 100 (18):10331-10334

Lichtenstein G, Baldi R, Villalba L, Hoces D, Baigún R, Laker J (2008) Vicugna vicugna. The IUCN Red List of Threatened Species. e.T22956A9402796.ISSN 2307-8235

Marín JC (2004) Filogenia molecular, filogeografía y domesticación de camelidos sudamericanos (ARTIODACTYLA: CAMELIDAE). PhD thesis, Universidad de Chile, Santiago.

Marín JC, Casey CS, Kadwell M, Yaya K, Hoces D, Olazabal J et al. (2007) Mitochondrial phylogeography and demographic history of the vicuna: implications for conservation. Hered (Edinb) 99 (1):70-80

Marín JC, Gonzalez BA, Poulin E, Casey CS, Johnson WE (2013) The influence of the arid Andean high plateau on the phylogeography and population genetics of guanaco (Lama guanicoe) in South America. Mol Ecol 22(2):463-482

Marín JC, Spotorno A, Gonzalez B, Bonacic C, Wheeler J, Casey C et al. (2008) Mitochondrial DNA variation and systematics of the guanaco (Lama guanicoe: Artiodactyla: Camelidae). J Mammal $89: 269-281$

Metcalf JL, Turney C, Barnett R, Martin F, Bray SC, Vilstrup JT et al. (2016) Synergistic roles of climate warming and human occupation in Patagonian megafaunal extinctions during the Last Deglaciation. Sci Adv 2(6):e1501682

Narum S (2006) Beyond Bonferroni: Less conservative analyses for conservation genetics. Conserv Genet 7:783-787

Nichols R, Beaumont M (1996) Is it ancient or modern history that we can read in the genes? In: Hochberg M, Clobert J, Barbault R (eds) Apects of the genesis and maintenance of biological diversity. Oxford University Press, Oxford

Park S (2001) Trypanotolerance in West African cattle and the population genetic effects of selection. $\mathrm{PhD}$ thesis, University of Dublin

Penedo M, Caetano A, Cordova K (1998) Microsatellite markers for South American camelids. Anim Genet 29:411-412 
Peter BM, Wegmann D, Excoffier L (2010) Distinguishing between population bottleneck and population subdivision by a Bayesian model choice procedure. Mol Ecol 19(21):4648-4660

Plummer M, Best N, Cowles K, Vines K (2006) Coda: output analysis and diagnostic for MCMC. R News 6:7-11

Pritchard JK, Stephens M, Donnelly P (2000) Inference of population structure using multilocus genotype data. Genetics 155 (2):945-959

R Development Core Team (2009) R: A language and environment for statistical computing. R Foundation for Statistical Computing. Vienna, Austria

Ramos-Onsins SE, Rozas J (2002) Statistical properties of new neutrality tests against population growth. Mol Biol Evol 19 (12):2092-2100

Romiguier J, Gayral P, Ballenghien M, Bernard A, Cahais V, Chenuil A et al. (2014) Comparative population genomics in animals uncovers the determinants of genetic diversity. Nature 515 (7526):261-263

Rosenberg N (2004) DISTRUCT: a program for the graphical display of population structure. Mol Ecol Notes 4:137-138

Ross KG (2001) Molecular ecology of social behaviour: analyses of breeding systems and genetic structure. Mol Ecol 10(2):265-284

Rousset F (2008) genepop'007: a complete re-implementation of the genepop software for Windows and Linux. Mol Ecol Resour 8 (1):103-106

Rozas J, Sanchez-DelBarrio JC, Messeguer X, Rozas R (2003) DnaSP, DNA polymorphism analyses by the coalescent and other methods. Bioinformatics 19(18):2496-2497

Sarno R, Franklin W, O'Brien S, Johnson W (2001) Patterns of mtDNA and microsatellite variation in an island and mainland population of guanacos in southern Chile. Anim Conserv 4:93-101

Sarno RJ, David VA, Franklin WL, O'Brien SJ, Johnson WE (2000) Development of microsatellite markers in the guanaco, Lama guanicoe: utility for South American camelids. Mol Ecol 9 (11):1922-1924

Shockey B, Salas-Gismondi R, Baby P, Guyot J, Baltazar M, Huaman L et al. (2009) New Pleistocene Cave Faunas of the Andes of
Central Peru: radiocarbon ages and the survival of low latitude, Pleistocene DNA. Palaeontol Electron 12:15A

Storz JF, Beaumont MA (2002) Testing for genetic evidence of population expansion and contraction: an empirical analysis of microsatellite DNA variation using a hierarchical Bayesian model. Evolution 56(1):154-166

Taberlet P, Griffin S, Goossens B, Questiau S, Manceau V, Escaravage $\mathrm{N}$ et al. (1996) Reliable genotyping of samples with very low DNA quantities using PCR. Nucleic Acid Res 24:3189-3194

Thompson LG, Mosley-Thompson E, Brecher H, Davis M, Leon B, Les D et al. (2006) Abrupt tropical climate change: past and present. Proc Natl Acad Sci USA 103(28):10536-10543

van Oosterhout C, Hutchinson W, Willis D, Shipley P (2004) MICROCHECKER: software for identifying and correcting genotyping errors in microsatellite data. Mol Ecol Notes 4:535-538

Watterson G (1975) On the number of segregating sites. Theor Popul Biol 7:256-276

Weeks AR, Stoklosa J, Hoffmann AA (2016) Conservation of genetic uniqueness of populations may increase extinction likelihood of endangered species: the case of Australian mammals. Front Zool 13:31

Wheeler J (1995) Evolution and present situation of the South American camelidae. Biol J Linn Soc 54:271-295

Wheeler J (2012a) South American camelids - past, present and future. J Camelid Sci 5:1-24

Wheeler J, Hoces D, Bruford M (2006) Actas IV Congreso Mundial sobre Camélidos. In: Miragaya M, Olivera D, Puig S (eds). Fundación biodiversidad, FIDA, CFI, Fundación Biodiversidad. Catamarca (Argentina), pp 76

Wheeler J, Pires-Ferreira E, Kaulicke P (1976) Preceramic animal utilization in the Central Peruvian Andes. Science 194:483-490

Wheeler JC (2012b) South American camelids - past, present and future. J Camelid Sci 5:1-24

Wheeler JC, Russel AJF, Redden H (1995) Llamas and Alpacas: preconquest breeds and post-conquest hybrids. J Archaelogical Sci 22:833-840

Wilson GA, Rannala B (2003) Bayesian inference of recent migration rates using multilocus genotypes. Genetics 163(3):1177-1191 